\title{
Heterogeneous Expectations and Speculative Behavior in Insurance-Linked Securities
}

\author{
Min Zheng ${ }^{1,2}$ \\ ${ }^{1}$ China Institute for Actuarial Science, Central University of Finance and Economics, Beijing 100081, China \\ ${ }^{2}$ School of Management, University of Chinese Academy of Sciences, Beijing 100190, China
}

Correspondence should be addressed to Min Zheng; zhengm@cufe-ins.sinanet.com

Received 26 September 2014; Accepted 23 February 2015

Academic Editor: Driss Boutat

Copyright (C) 2015 Min Zheng. This is an open access article distributed under the Creative Commons Attribution License, which permits unrestricted use, distribution, and reproduction in any medium, provided the original work is properly cited.

Within the framework of heterogeneous agent models, this paper analyzes the impact factors on the issuance of an insurancelinked security (ILS), and gives an ILS pricing formula and the conditions of existence and stability of the issue price. We consider two cases: fixed supply and flexible supply. We find that, in the fixed volume case, to assure the successful issuance of an ILS, an appropriate volume of the ILS is necessary, and to attract investors, the ILS should pay a positive premium which can help investors to enhance the efficient frontier of their portfolio. In the flexible supply case, we show that the issue price of an ILS is given by the weighted average of different beliefs about the discounted ILS return, and the stability of the issue price depends on the numbers of investors and sponsors and the extrapolation rate to the ILS of investors. In addition, whether an ILS has the hedging ability to sponsors depends on their own understanding about the ILS coupon and the relationship between the recovery from the ILS and their liability, but how much the risk of sponsors can be hedged relies on the ILS coupon expected by investors.

\section{Introduction}

The traditional mechanism for transferring and managing risks in the insurance industry mainly is reinsurance. However, natural catastrophe is becoming more frequent and severe [1] and remarkable mortality improvement has led to the growth of the population of older people [2-4], which has a significantly negative impact on pension plans and annuity providers. The traditional reinsurance route for managing those risks is capacity constrained because traditional reinsurance only operates efficiently in managing relatively small, uncorrelated risks and in facilitating efficient information sharing between cedents and reinsurers. When the magnitude of potential losses and the correlation of risks increase, the efficiency of the reinsurance model breaks down and the cost of capital required to maintain accepted solvency levels may become uneconomical (see [5]). Therefore, the securitization model (for reviews of those models, see Barrieu and Albertini [6]) has been employed by more and more insurers eager to transfer risk and tap new sources of capital market funding. By transferring risks to the capital market, insurance-linked securities (ILSs) can help insurers to manage their risks, simplifying risk transfer, bringing in much needed loss absorbing capacity, and providing an efficient way (such as bonds and options) to match risk, capital, and reward in different parts of the world. In fact, an ILS is not only a way to manage the risks faced by insurers, but also an attractive diversifying tool to investors in the capital market because it is very low correlated with traditional asset classes, given that its returns do not depend on economic factors, but rather on the occurrence of events such as the influenza pandemic, as for mortality bonds. Thus, both insurance industry and investors have strong motivations to further engage in this market. While insurers are able to manage their risks more efficiently, investors benefit from additional diversification opportunities and attractive yields.

But while ILSs have cemented their place as a complementary alternative to reinsurance, they still have a long way to go before they can realize their full potential. To 2012, ILSs represent only approximately $14 \%$ of the total capacity (the datum comes from $\mathrm{PwC}$ [7]) provided to cedents for property catastrophe reinsurance protection. Relative to reinsurance capacity overall, the market for ILSs remains comparably 
small. In addition, the secondary market for ILSs is also very immature such that the liquidity of ILSs is inadequate. Therefore, there are a number of issues that need to be dealt with if insurance risk is to be transformed into marketable securities on a larger scale. After all, a critical mass of new issuance and continuous issuance activity are needed to broaden the investor base, reduce transaction costs, and fully lever the economic benefits of these instruments. Among those, the structuring of ILSs, especially pricing, becomes a key point. Accordingly, to develop this emerging market, actuaries and financial economists have begun to make considerable efforts to improve their structure and take challenges to connect financial and insurance pricing theories.

While different methods of how to price such securities have been proposed in recent literature, no consensus has been reached. There are mainly two directions to do it. The first is a distortion approach such as the Wang transform (see, e.g., [8]). The Wang transform was applied to mortality/ longevity securitization by Lin and Cox $[9,10]$, Cox et al. [11], Bauer and Ruß [12], Denuit et al. [13], and Chen and Cox [14]. However, due to the insufficient price data of ILSs, parameters in the Wang transform usually cannot be determined uniquely except for adding some artificial constraints like Chen and Cox [14]. In addition, the risk premium implied by the Wang transform is not consistent. For example, arbitrage opportunities may arise as soon as multiple longevity-linked securities based on different cohorts are traded. Even if only one longevity-linked security is considered, the disproportional risk premium allocation contests the adequacy of an application of the Wang transform for pricing longevity derivatives, shown in Bauer et al. [15].

The second method of pricing ILSs is an arbitrage-free approach favored by many recent authors (see, e.g., [16-22] and references therein). This is based on a long established financial economic theory that states that, even in an incomplete market, if the overall market is arbitrage-free, then there exists at least one such risk-neutral measure that we can use to calculate fair prices. The problem is then to identify what this might be, given the paucity of reference securities against which we can calibrate a risk-neutral pricing measure. Recently, some researchers, for example, Li [23] and Li and $\mathrm{Ng}$ [24], have implemented the no-arbitrage approach by a method called canonical valuation. This method identifies a risk-neutral measure by minimizing the Kullback-Leibler information criterion, subject to market price constraints. However, one may also question if the identified risk-neutral measure is applicable to securities that are linked to different liquidity profiles. Therefore, the classical methodology of risk-neutral pricing cannot be used carelessly and many insurance principles lack the ability to produce arbitrage-free prices.

Besides the aforementioned methods, there are other methodologies proposed to price an ILS. For example, Friedberg and Webb [25] apply the capital asset pricing model (CAPM) and the consumption capital asset pricing model (CCAPM) to quantify risk premiums for potential investors in mortality bonds. However, the authors acknowledge that there is likely in existence a "mortality premium puzzle" similar to the well-known "equity premium puzzle" (see
[26]) implying higher mortality risk premiums than these economic models would suggest.

In addition, Egami and Young [27] and Cox et al. [28] use utility indifference to price insurance securitization. Milevsky et al. [29] and Bayraktar et al. [30] develop a theory for pricing nondiversifiable mortality risk in an incomplete market. They postulate that an issuer of a life contingency requires compensation for the risk according to a prespecified instantaneous Sharpe ratio. Cox and Pedersen [31] use the framework of representative agent equilibrium to price the catastrophe bond. Bauer et al. [15] review, compare, and comment on these different approaches.

However, the methods mentioned above emphasize the peculiarity of an ILS in risks but ignore its basic economics. Fundamentally, an ILS is a financial facility which allows for matching the demand of parties (sponsors, mainly insurers) who desire to lay off risks with the supply of dedicated risk transfer capacity provided by investors seeking exposure to insurance risk. Therefore, the ILS price should balance the requirements of both ILS sponsors and investors. While sponsors wish to cover their underlying portfolio risk (e.g., to minimize basis risk), investors need to be persuaded that they are approaching their investments cogently and correctly (e.g., to maximize wealth utility). So far, only limited academic research has been devoted to the ILS pricing based on the economic concept: demand and supply except Zhou et al. [32] and Chen et al. [33]. The former apply an economic (tâtonnement) pricing approach to calculate the equilibrium price of the mortality-linked security at which supply is equal to demand and the market is cleared. The latter, within the framework of supply and demand, study the effects of risk aversion and ambiguity aversion on mortality-linked securities by incorporating the smooth ambiguity preferences into the indifference pricing approach and the tâtonnement pricing approach. Those papers only consider an ILS itself and regard an ILS as a risk management tool to sponsors rather than a new investment tool to investors. In fact, an important reason of an ILS transferring insurance-linked risks to the capital market is that investors think that the ILS with a low correlation to traditional asset classes can be used as a diversifying tool which works only when the ILS and traditional asset classes are put into the same investment portfolio.

In addition, except different requirements of them, sponsors and investors also have different beliefs about an ILS because either they could assess a publicly available information set, but they can interpret the information in different ways (see, e.g., [34-37], among others), or the information used by them is different (see, e.g., [38-40], among others). Furthermore, all decisions or requirements of sponsors and investors would be based on their own beliefs.

Therefore, in this paper, we assume that different agents have different beliefs because of the first explanation; that is, sponsors and investors have the same information, but they interpret it in different ways. In addition, we assume that to hedge their risk, according to their own beliefs and requirement; sponsors issue an ILS which is, as a new investment opportunity, added into the portfolio of investors to maximize their investment objective based on 
their own beliefs. Thus, the ILS trading depends not only on its own demand and supply because of different beliefs and requirements, but also on the reaction between the insurance market and the capital market.

This research contributes to the existing literature in several ways. First, we connect the capital market and the insurance market by an ILS and investors can choose a suitable investment strategy between an ILS and traditional assets in order to maximize their objective based on their own beliefs. To our best knowledge, this paper is among the first of its kind to study the interaction between the insurance market and the capital market by an ILS. Second, we formulate the economic pricing approach by putting an ILS and traditional assets into investors' portfolio, which intrinsically establishes the link of returns between the ILS and traditional assets. That is, to assure the successful issuance of an ILS, the expected excess return of the ILS should be equal to the expected excess return of the traditional risky asset adjusted by the return sensitivity between these two assets, plus an "abnormal" risk premium which depends on many factors such as the issuance volume of the ILS, the market fraction of investors, the risk aversion coefficient of investors, and the correlation between the ILS and the traditional risky asset. Third, we show that heterogeneity in beliefs is the basic condition of the successful issuance of an ILS, and test the earning ability of an ILS to investors and its hedging effectiveness to sponsors. Those results well show the roles of an ILS to sponsors and investors and the relationship between the insurance market and the capital market.

The remainder of the paper is organized as follows. Section 2 considers that an ILS is to be issued in a fixed amount and investors can make their investment strategy between the ILS and traditional assets based on their own beliefs. An ILS pricing formula is given under a Walrasian equilibrium and the ability of the ILS to increase investment performance (i.e., to enhance the efficient frontier) from investors' perspective is analyzed. In Section 3, a general model is given where, except for investors in the market, there are sponsors who supply an ILS in order to hedge their risk from their contingent liability. A pricing formula of the ILS is given and the hedging ability of the ILS to sponsors is tested. Section 4 concludes the paper with some suggestions for possible extensions. For ease of exposition, most proofs are in an appendix.

\section{Fixed Supply}

We consider that there is an insurance-linked security (ILS in brief, e.g., a mortality-linked security) depending on one type of insurance-linked risks, denoted by $q$ (e.g., mortality risk), to be issued in a Walrasian market at time 0 and to be due at time 1 . The issue price is denoted by $\mathscr{P}_{o}$, the redemption price is denoted by $\mathscr{P}_{r}$, and the coupon per unit is denoted by $g(q)$. In this market, there already exist two types of traditional asset classes, one riskless asset (e.g., bonds) perfectly elastically supplied at gross return $R=1+r(>1)$ at time 1 and one risky asset (e.g., stock index, like S\&P 500) with the price (ex-dividend $y$ ) $\mathcal{S}_{o}$ per share at time 0 and the price $\delta_{r}$ at time 1 .
There is only one type of investors (denoted by agent $A$ ) with the initial wealth $\omega_{A}$ in the market. Agent $A$ wants to arrange his initial wealth among the ILS, the risky asset, and his saving account to maximize his wealth utility at the due day of the ILS. Assume agent $A$ wants to buy $\Theta_{A}$ units of the ILS and $\Phi_{A}$ shares of the risky asset and then put the left money $\left(\omega_{A}-\Theta_{A} \mathscr{P}_{o}-\Phi_{A} \mathcal{\delta}_{o}\right)$ in his saving account. Then, at the due day of the ILS, the wealth which agent $A$ can finally get is

$W_{A}=\omega_{A} R+\Theta_{A}\left(g(q)+\mathscr{P}_{r}-R \mathscr{P}_{o}\right)+\Phi_{A}\left(y+\delta_{r}-R \delta_{o}\right)$.

Assume that agent $A$ is a myopic mean-variance maximizer based on his own beliefs. Thus, the objective of agent $A$ can be formulated as follows:

$$
(\mathrm{OP})^{A}: \sup _{\left\{\Theta_{A}, \Phi_{A}\right\}} E^{A}\left(W_{A}\right)-\frac{k_{A}}{2} V^{A}\left(W_{A}\right),
$$

where $E^{A}$ and $V^{A}$ denote the "beliefs" of agent $A$ about the expectation and variance, and $k_{A}$ denotes the risk aversion coefficient of agent $A$.

By the first order condition, the optimal positions held by agent $A$ are

$$
\begin{aligned}
& \Theta_{A}=\frac{E^{A}\left(R_{P}\right)-k_{A} \Phi_{A} \operatorname{cov}_{A, P S}}{k_{A} \sigma_{A, P}^{2}}, \\
& \Phi_{A}=\frac{E^{A}\left(R_{S}\right)-k_{A} \Theta_{A} \operatorname{cov}_{A, P S}}{k_{A} \sigma_{A, S}^{2}},
\end{aligned}
$$

where $R_{P}=g(q)+\mathscr{P}_{r}-R \mathscr{P}_{o}$ and $R_{S}=y+\mathcal{S}_{r}-R \mathcal{S}_{o}$ denote the excess returns of the ILS and the risky asset, respectively, $\operatorname{cov}_{A, P S}=\operatorname{Cov}^{A}\left(R_{P}, R_{S}\right), \sigma_{A, P}^{2}=V^{A}\left(R_{P}\right)$, and $\sigma_{A, S}^{2}=V^{A}\left(R_{S}\right)$, where $\operatorname{Cov}^{A}(\cdot, \cdot)$ denotes the "belief" of agent $A$ about the covariance. Optimal positions in (3) illustrate how capital and insurance markets interact with each other because, as a bridge connecting the insurance market and the capital market, the demands of agent $A$ on the ILS and the risky asset affect each other measured by $\operatorname{cov}_{A, P S}$.

2.1. Equilibrium and Pricing. Assume that the supply of the ILS units is fixed, denoted by $l_{I}(>0)$; then the equilibrium of demand and supply of the ILS implies

$$
n_{A} \Theta_{A}=l_{I},
$$

where $n_{A}$ represents the number of agent $A$. Considering that the risky asset is a mature asset and its liquidity is sufficient, we assume that, in the paper, the demand and supply of the risky asset have no constraint. Combining (4) with (3), we can get the relationship of the expected excess returns between the ILS and the risky asset as follows.

Proposition 1. The excess return of the ILS estimated by agent A should satisfy the following relationship:

$$
E^{A}\left(R_{P}\right)=\alpha_{A}+\beta_{A} E^{A}\left(R_{S}\right),
$$


where $\alpha_{A}=\left(l_{I} / N_{A, P}\right)\left(1-\rho_{A, P S}^{2}\right)$ denotes the "abnormal" excess return estimated by agent $A, \beta_{A}=\operatorname{cov}_{A, P S} / \sigma_{A, S}^{2}$ is the sensitivity of the expected excess return of the ILS to the expected excess return of the risky asset by agent $A, N_{A, P}=$ $n_{A} /\left(k_{A} \sigma_{A, P}^{2}\right)$ is the adjusted market fraction of agent $A$ by his risk aversion coefficient and his estimated variance of the $I L S$, and $\rho_{A, P S}=\operatorname{cov}_{A, P S} /\left(\sigma_{A, P} \sigma_{A, S}\right)$ measures the correlation coefficient between the ILS and the risky asset estimated by agent $A$.

From Proposition 1, we can see that, to agent $A$, (5) gives an ILS pricing formula with the CAPM format (note that it just has the CAPM format but is not the traditional CAPM because (5) connects the excess return of the ILS with the one of the risky asset rather than the one of the market portfolio) plus the positive premium $\alpha_{A}$. If we can regard the return given by the CAPM format as a benchmark return required by investors, then the positive premium of the ILS can be regarded as the penalty term or the compensation for the new risk borne because if it wanted to attract investors to change their investment preference to invest the ILS, it needed to pay some extra premium to investors, which also gives an explanation of the "mortality premium puzzle" appearing in mortality bonds shown in Friedberg and Webb [25]. The positive premium depends on the correlation between the ILS and the risky asset, the volume of the ILS, and the adjusted market fraction of investors. The larger the supply of the ILS is, the higher the premium is needed to attract investors. When the adjusted market fraction of agent $A$ is lower, which corresponds to the lower demand of the ILS, then agent $A$ expects the higher excess return from the ILS. When agent $A$ thinks the insurance market and the capital market become more intertwined, that is $\rho_{A, P S}^{2}$ is closer to 1 , convergence in the pricing of risk generally increases and there is less extra premium of the ILS expected by agent $A$.

2.2. Efficient Frontier. The pricing mechanism of (5) gives a relationship of the excess returns between the ILS and the traditional risky asset. Under the pricing relationship, investors see the relative value of the ILS as the diversifying asset with superior returns. It looks very attractive to investors because it is useful to enhance investors' efficient frontier.

In fact, we know that if agent $A$ only has the risky asset as his investment tool, then his optimal position $\widehat{\Phi}_{A}$ in the risky asset and the corresponding efficient frontier of his optimal wealth $\widehat{W}_{A}$ expected by him are, respectively, given by

$$
\begin{gathered}
\widehat{\Phi}_{A}=\frac{E^{A}\left(R_{S}\right)}{k_{A} \sigma_{A, S}^{2}}, \\
E^{A}\left(\widehat{W}_{A}\right)=\omega_{A} R+\operatorname{SR}^{A}\left(\widehat{W}_{A}\right) * \sigma^{A}\left(\widehat{W}_{A}\right),
\end{gathered}
$$

where $\sigma^{A}(\cdot)=\sqrt{V^{A}(\cdot)}$ and the slope of the efficient frontier $\mathrm{SR}^{A}\left(\widehat{W}_{A}\right)$ is given by the reward-to-variability ratio or the Sharpe ratio of the risky asset estimated by agent $A$; that is, $\mathrm{SR}^{A}\left(\widehat{W}_{A}\right)=E^{A}\left(R_{S}\right) / \sigma_{A, S}$. However, if the ILS is added into the portfolio, from the optimal positions of investors given

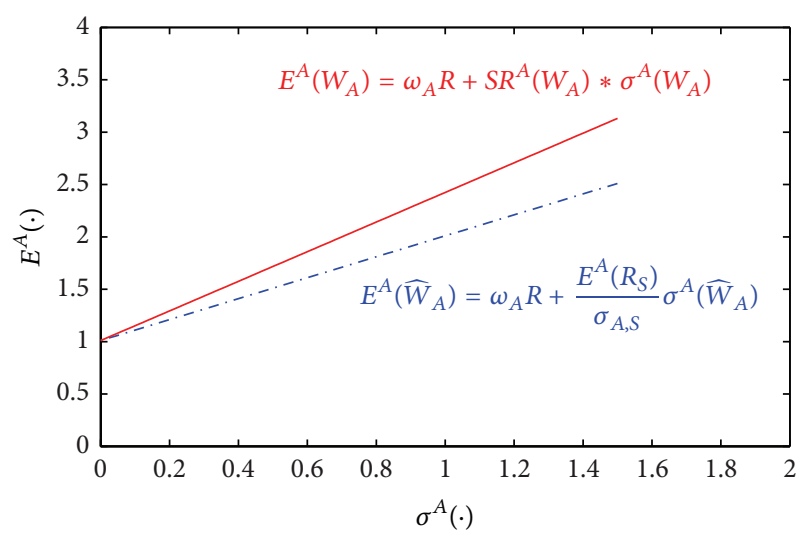

FIGURE 1: Comparison of the efficient frontiers between the portfolios with and without the ILS at $\rho_{A, P S}=0$.

in (3), we can calculate the new efficient frontier of agent $A$ given by

$$
E^{A}\left(W_{A}\right)=\omega_{A} R+\mathrm{SR}^{A}\left(W_{A}\right) * \sigma^{A}\left(W_{A}\right)
$$

where

$$
\mathrm{SR}^{A}\left(W_{A}\right)=\sqrt{\alpha_{A} \frac{l_{I}}{N_{A, P} \sigma_{A, P}^{2}}+\left(\frac{E^{A}\left(R_{S}\right)}{\sigma_{A, S}}\right)^{2}} \geq \frac{E^{A}\left(R_{S}\right)}{\sigma_{A, S}} .
$$

Thus, the slope of the new efficient frontier depends not only on the reward-to-variability ratio of the risky asset but also on the "abnormal" excess return from the ILS. Therefore, given its relatively low correlation with the risky asset and its attractive return, the ILS has the ability to improve the efficient frontier of the traditional portfolio, as illustrated in Figure 1.

2.3. Tâtonnement Process. Note that the ILS is issued in a Walrasian market and the buyer of the ILS makes his investment decision based on his own beliefs. Usually, the first guess of the issue price of the ILS does not clear the market and there is a groping process, also called a tâtonnement process (we refer the reader for more details about the tâtonnement process to Zhou et al. [32] and references therein) to generate the issue price. In the Walrasian market, prices are announced (perhaps by an "auctioneer") and an investor states how much of the asset he would like to hold based on his own objective. No transactions take place at disequilibrium prices.

For the ILS, we let $p_{t}$ denote the groping price of the ILS at the $t$ th groping. We consider that agent $A$ makes his investment decision based on his forecast about the redemption price, the excess returns, and the historical groping prices of the ILS. In particular, we assume that agent $A$ is a trend chaser and he forecasts the redemption price $\mathscr{P}_{r}$ of the ILS by the technical method given by

$$
e_{t}^{A}\left(\mathscr{P}_{r}\right)=p_{t-1}+\delta_{A}\left(p_{t-1}-p_{t-1}^{\sharp}\right),
$$

where $e_{t}^{A}(\cdot)$ represents the conditional expectation of agent $A$ at the $t$ th groping based on the past information $\left\{p_{s}\right\}_{s<t}$, 


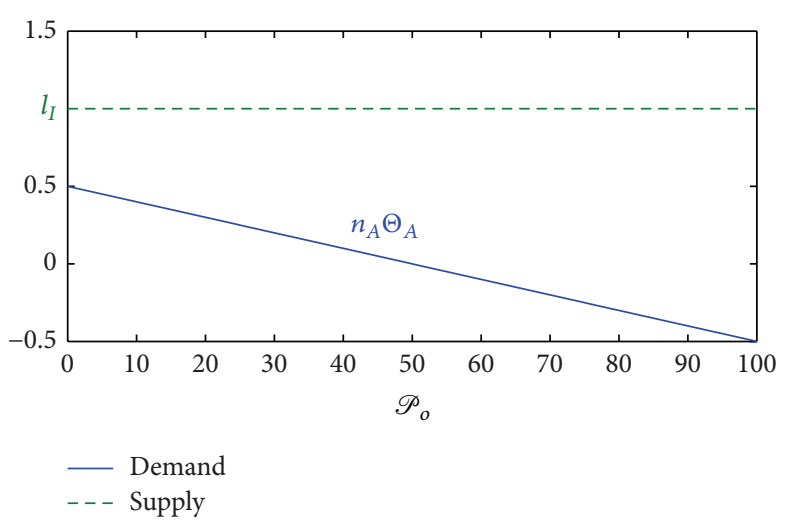

(a) Consider $l_{I}>\left(\mathscr{G}_{A}-\beta_{A} E^{A}\left(R_{S}\right)\right)\left(N_{A, P} /\left(1-\rho_{A, P S}^{2}\right)\right)$

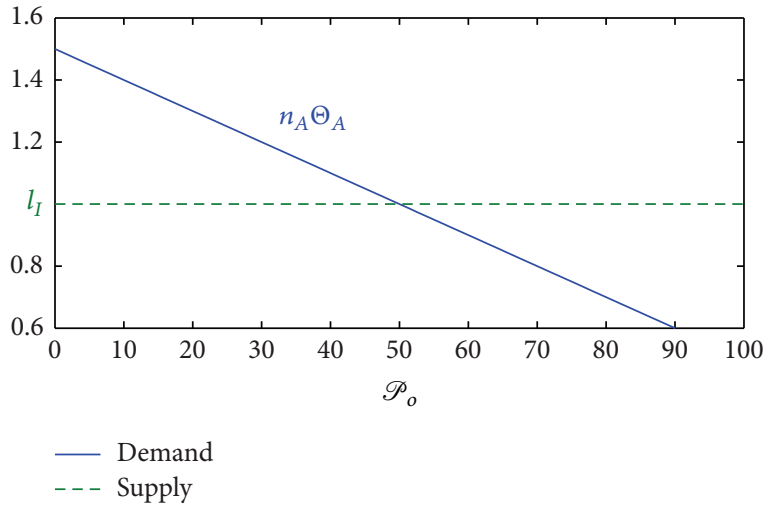

(b) Consider $l_{I}<\left(\mathscr{G}_{A}-\beta_{A} E^{A}\left(R_{S}\right)\right)\left(N_{A, P} /\left(1-\rho_{A, P S}^{2}\right)\right)$

FIGURE 2: Possible equilibrium solutions of system (11), where the vertical axes represent the amounts of the demand or supply corresponding to different equilibrium prices.

$\delta_{A}>0$ measures the extrapolation rate to the historical information of the ILS by agent $A$, and $p_{t-1}^{\sharp}$ is the reference price of the ILS adopted by agent $A$. If $p_{t-1}>(<) p_{t-1}^{\sharp}$, then agent $A$ thinks that the redemption price of the ILS will be higher (lower) and the size is determined by his extrapolation rate and the price difference $p_{t-1}-p_{t-1}^{\sharp}$. For more explanations about the technical method, we refer the reader to Brock and Hommes [41]. In addition, we assume that the estimations of agent $A$ about the expectation of the ILS coupon, the variance of the ILS excess return, and the covariance of the excess returns between the ILS and the risky asset are constant; that is, $e_{t}^{A}(g(q))=E^{A}(g(q))=\mathscr{G}_{A}$, $v_{t}^{A}\left(R_{P}\right)=\sigma_{A, P}^{2}$, and $\operatorname{cov}_{t}^{A}\left(R_{P}, R_{S}\right)=\operatorname{cov}_{A, P S}$, where $v_{t}^{A}(\cdot)$ and $\operatorname{cov}_{t}^{A}(\cdot, \cdot)$, respectively, are the "beliefs" of agent $A$ about the conditional variance and covariance corresponding to the conditional expectation $e_{t}^{A}(\cdot)$.

For the risky asset, it is a mature asset and does not need to determine the issue price any longer. Therefore, the beliefs of agent $A$ about the risky asset remain invariant during the whole groping process; that is, $e_{t}^{A}\left(R_{S}\right)=E^{A}\left(R_{S}\right)$ and $v_{t}^{A}\left(R_{S}\right)=$ $\sigma_{A, S}^{2}$

The objective of agent $A$ is to maximize his mean-variance wealth utility based on his own beliefs at the $t$ th groping; that is,

$$
\sup _{\left\{\theta_{A, t}, \phi_{A, t}\right\}} e_{t}^{A}\left(w_{A, t}\right)-\frac{k_{A}}{2} v_{t}^{A}\left(w_{A, t}\right)
$$

where $w_{A, t}=\omega_{A} R+\theta_{A, t} R_{P}+\phi_{A, t} R_{S}$ and $\theta_{A, t}$ and $\phi_{h, t}$ are agent $A$ 's demands, respectively, of the ILS and the risky asset at the $t$ th groping.

By the equilibrium condition $n_{A} \theta_{A, t}=l_{I}$ and the optimal positions of (10), we can get the evolutionary process of the groping price as follows:

$$
\begin{aligned}
R p_{t}= & \mathscr{G}_{A}+p_{t-1}+\delta_{A}\left(p_{t-1}-p_{t-1}^{\sharp}\right) \\
& -\beta_{A} E^{A}\left(R_{S}\right)-\frac{l_{I}}{N_{A, P}}\left(1-\rho_{A, P S}^{2}\right) .
\end{aligned}
$$

We assume that agent $A$ uses a two-period moving average price as the reference price; that is, $p_{t}^{\sharp}=\left(p_{t-1}+p_{t-2}\right) / 2$. Then, we can get the equilibrium price of the ILS.

Proposition 2 (existence and stability of equilibrium). Let

$$
p^{*}=\frac{1}{r}\left(\mathscr{G}_{A}-\beta_{A} E^{A}\left(R_{S}\right)-\frac{l_{I}}{N_{A, P}}\left(1-\rho_{A, P S}^{2}\right)\right) .
$$

If $p^{*}>0$, then system (11) has a unique equilibrium solution $\mathscr{P}_{o}=p^{*}$ which is stable as $\delta_{A}<2 R$.

As said earlier, there exist transactions only at equilibrium and thus the equilibrium price given by (12) is the final issue price of the ILS; that is, $\mathscr{P}_{o}=p^{*}$. However, whether this equilibrium price can really be regarded as the issue price depends on some factors. The first two factors are the issuance volume $l_{I}$ and the return of the ILS. Note that if $\mathscr{G}_{A}<\beta_{A} E^{A}\left(R_{S}\right)$ which means agent $A$ feels that the return from the ILS is comparatively low, then agent $A$ would not purchase the ILS and furthermore the issuance of the ILS is aborted. If $\mathscr{G}_{A}>\beta_{A} E^{A}\left(R_{S}\right)$, but the issuance volume of the ILS is so high to exceed the benchmark level given by $\left(\mathscr{G}_{A}-\beta_{A} E^{A}\left(R_{S}\right)\right)\left(N_{A, P} /\left(1-\rho_{A, P S}^{2}\right)\right)$, then the equilibrium price is negative which cannot exist in the real world, as illustrated in Figure 2(a). In fact, the negative equilibrium price corresponds to the failure of the ILS issuance because the overall volume of the new issuance is beyond the investors' ability to bear risk. Therefore, to assure the successful issuance of the ILS, a suitable return and an appropriate volume of the ILS satisfying

$$
\mathscr{G}_{A}>\beta_{A} E^{A}\left(R_{S}\right), \quad l_{I}<\left(\mathscr{G}_{A}-\beta_{A} E^{A}\left(R_{S}\right)\right) \frac{N_{A, P}}{1-\rho_{A, P S}^{2}},
$$

are necessary; see Figure 2(b).

Another factor affecting the issuance of the ILS is the extrapolation rate to the ILS of investors (i.e., agent $A$ in the paper). From Proposition 2, we know that only when the 


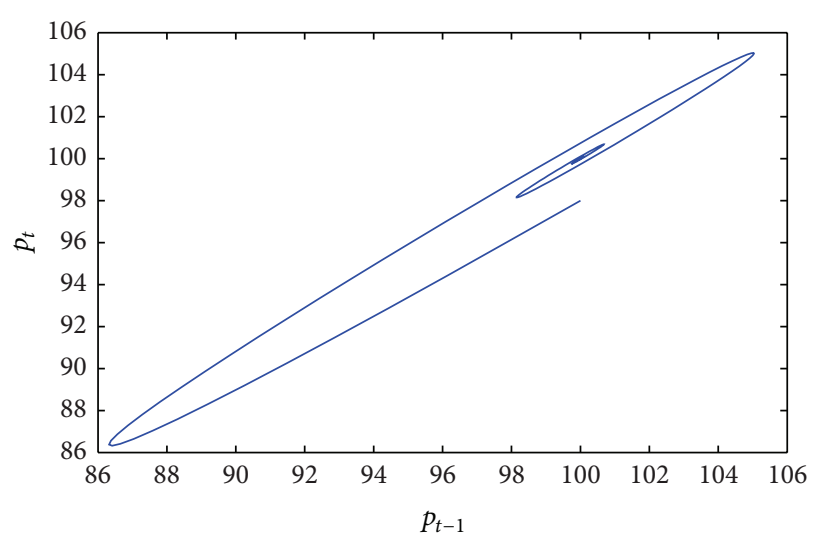

(a) Stable as $\delta_{A}<2 R$

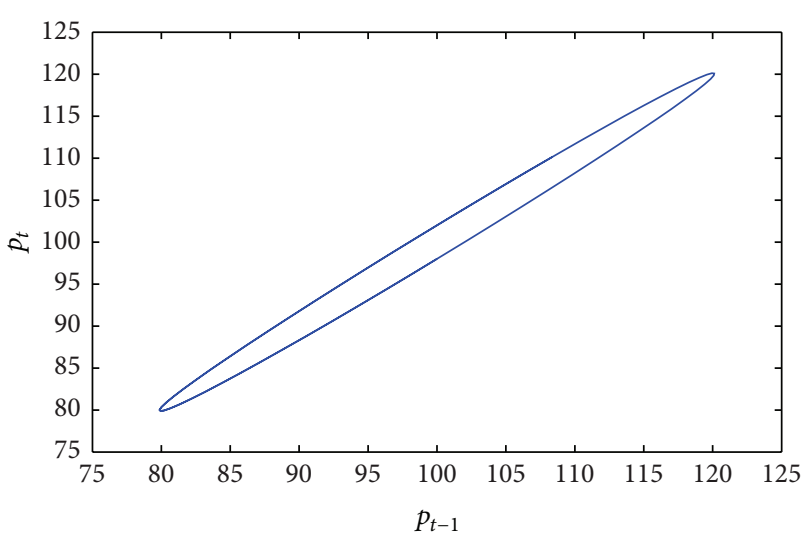

(b) Unstable at $\delta_{A}=2 R$

FIGURE 3: Stability of the equilibrium price of the ILS, where $p^{*}=100$.

extrapolation rate $\delta_{A}$ of agent $A$ is small, then the equilibrium price is stable as in Figure 3(a). When the extrapolation rate of agent $A$ is too high, especially at $\delta_{A}=2 R$, the groping process always fluctuates around the equilibrium price instead of converging to a reasonable price; see Figure 3(b). This gives another explanation to the unsuccess of the ILS issuance which is because investors extrapolate their estimation to the future so strong that the auctioneer continues adjusting the issue price, and therefore it is not able to arrive at a consensus price. If $\delta_{A}>2 R$, then the price would continue increasing which means both sides of demand and supply cannot reach an agreement and the issuance of the ILS fails.

In addition, the equilibrium price also depends on the risk aversion of investors, the estimation of the ILS variance, and the number of investors. Like the volume factor, the very high risk aversion, high variance estimation, and/or few number of investors all could result in a failure of the ILS issuance.

\section{Flexible Supply}

In Section 2, we consider the fixed supply case of an insurance-linked security and find that a higher issuance volume of the ILS is possible to result in a failure of the ILS issuance because it could exceed the investors' ability to bear risk. In the real market, issuers/sponsors should consider the capacity of the capital market and their own objective, such as the risk minimization, to determine the issuance size of an insurance-linked security. Therefore, in this section, we consider that the issuance volume of an insurance-linked security depends on the market situation.

Similar to Zhou et al. [32], suppose agent $I$ is a sponsor (mainly an insurer) of an insurance-linked security, who supplies the volume of the ILS. Agent $I$ likes to sponsor the ILS because he is a protection buyer and wants to hedge the contingent liability coming from the insurance risk $q$, which is due at time 1 . We denote this amount by $f(q)$. However, usually there exists the mismatch between the liability and the recovery provided by the ILS, which is the hedging risk. Agent $I$ wants to adjust the issuance volume of the ILS to minimize his hedging risk. Suppose agent $I$ sponsors $\Theta_{I}$ units of the ILS. Then, the hedging risk (HR in brief) of agent $I$ is

$$
\mathrm{HR}=f(q)+\Theta_{I}\left(g(q)+\mathscr{P}_{r}-R \mathscr{P}_{o}\right)=f(q)+\Theta_{I} R_{P} .
$$

As mentioned before, different agents have different beliefs and requirements. We assume the objective of agent $I$ is to minimize the hedging risk and its volatility based on his own beliefs; that is,

$$
\inf _{\Theta_{I}} E^{I}(\mathrm{HR})+\frac{k_{I}}{2} V^{I}(\mathrm{HR}),
$$

where $E^{I}$ and $V^{I}$ denote the "beliefs" of agent $I$ about the expectation and variance, and $k_{I}$ denotes the risk aversion coefficient of agent $I$. In this section, similar to the setup of Section 2, we still consider that agent $A$ invests both in the ILS and in the risky asset, and $\Theta_{A}$ and $\Phi_{A}$ denote the positions, respectively, of the ILS and the risky asset held by agent $A$. Agent $A$ will choose $\Theta_{A}$ and $\Phi_{A}$ in order to maximize the mean-variance utility of his wealth based on his own beliefs at time 1. Assume that the net supply of the ILS is zero and then the clear condition of the ILS is

$$
n_{A} \Theta_{A}=n_{I} \Theta_{I},
$$

where $n_{h}$ is the number of agent $h(h=I, A)$.

Note that the ILS market is driven primarily by the sponsor's demand for protection: where there is no need for coverage, there is no market for an ILS. Therefore, to agent $I$, the proceeds of the ILS depend not only on the ILS coupon itself but also on the relationship between the ILS and his contingent liability measured by $\operatorname{cov}_{I, P f}=$ $\operatorname{Cov}^{I}\left(R_{P}, f(q)\right)$ which is the estimated covariance between the ILS return and the contingent liability by agent $I$. The covariance $\operatorname{cov}_{I, P f}$ adjusted by the risk aversion coefficient $k_{I}$ of agent $I$ reflects the protection ability of the ILS to the sponsor's risk. Therefore, we define $\mathbb{G}_{I}=E^{I}(g(q))+$ $k_{I} \operatorname{cov}_{I, P f}=\mathscr{G}_{I}+k_{I} \operatorname{cov}_{I, P f}$ as the adjusted coupon of the ILS and further $\mathscr{E}^{I}\left(R_{P}\right)=E^{I}\left(R_{P}\right)+k_{I} \operatorname{cov}_{I, P f}$ as the adjusted 
excess return of the ILS both expected by agent $I$. By the first order condition, we can get the optimal positions held by agents $I$ and $A$, respectively, as follows:

$$
\begin{gathered}
\Theta_{I}=-\frac{\mathscr{E}^{I}\left(R_{P}\right)}{k_{I} \sigma_{I, P}^{2}}, \\
\Theta_{A}=\frac{E^{A}\left(R_{P}\right)-k_{A} \Phi_{A} \operatorname{cov}_{A, P S}}{k_{A} \sigma_{A, P}^{2}}, \\
\Phi_{A}=\frac{E^{A}\left(R_{S}\right)-k_{A} \Theta_{A} \operatorname{cov}_{A, P S}}{k_{A} \sigma_{A, S}^{2}} .
\end{gathered}
$$

Optimal positions in (17) illustrate how the ILS demand and supply may be constrained by factors that affect reservation prices on either side of the market. In addition, to assure the successful issuance of the ILS, $\Theta_{I}$ should be positive; that is, $\mathscr{E}^{I}\left(R_{P}\right)=E^{I}\left(R_{P}\right)+k_{I} \operatorname{cov}_{I, P f}<0$. Thus, either $E^{I}\left(R_{P}\right)$ or $\operatorname{cov}_{I, P f}$ is negative. It means that the ILS could be issued successfully only when either agent $I$ expects that the issue price of the ILS is very high, but its coupon is very low, in which case agent $I$ can earn money by the issuance of the ILS, or agent $I$ estimates there is a significantly negative relationship between the ILS return and his liability, which implies that agent $I$ can use the ILS to hedge his liability risk. As follows, unless otherwise specified, we assume that $\mathscr{E}^{I}\left(R_{P}\right)<0$.

3.1. Issue Price. Similar to Section 2, to get the issue price of the ILS, we consider that there is a groping process such that the supply of agent $I$ matches the demand of agent $A$. In the whole groping process, we assume that the agents have the common information about the historical groping prices of the ILS and they update their beliefs about the redemption price of the ILS based on the common information but in different ways while they keep their beliefs about the expectation of the ILS coupon and the corresponding variance and covariance terms invariant.

As shown in Section 2.3, for agent $A$, he still adopts the technical method to estimate the redemption price of the ILS; that is,

$$
e_{t}^{A}\left(\mathscr{P}_{r}\right)=p_{t-1}+\delta_{A}\left(p_{t-1}-p_{t-1}^{\sharp}\right),
$$

where $\delta_{A}>0$ is the extrapolation rate of agent $A$ and the reference price $p_{t-1}^{\sharp}$ is determined by a two-period moving average; that is, $p_{t-1}^{\sharp}=\left(p_{t-1}+p_{t-2}\right) / 2$.

For agent $I$, he believes that the redemption price of the ILS should converge to its fundamental value $p^{\natural}$ estimated by himself which, similar to Brock and Hommes [41], is determined by its discounted proceeds as $p^{\natural}=\mathbb{G}_{I} / r$; that is, the belief of agent $I$ about the redemption price of the ILS $e_{t}^{I}\left(\mathscr{P}_{r}\right)$ at the $t$ th groping can be expressed as

$$
e_{t}^{I}\left(\mathscr{P}_{r}\right)=p_{t-1}+\delta_{I}\left(p^{\natural}-p_{t-1}\right)=\left(1-\delta_{I}\right) p_{t-1}+\delta_{I} p^{\natural},
$$

where $\delta_{I} \in[0,1]$ is the convergence speed of the ILS to its fundamental value adopted by agent $I$ and measures his confidence level about his estimation $p^{\natural}$. The higher the convergence speed, the quicker the price adjustment by agent I towards his estimated fundamental price of the ILS, which means agent $I$ is more confident about his estimation.

Note that insurance-linked securities are normally presented to investors as instruments having "very little" or "low" correlation with other assets in their portfolio, thus improving its diversification and therefore its efficient frontier (relating the expected return and the risk of the portfolio). As follows, unless otherwise specified, we assume $\operatorname{cov}_{A, P S}=0$. That is to say that agent $A$ thinks there is no correlation between the ILS and the risky asset. Denoting $N_{h, P}=$ $n_{h} /\left(k_{h} \sigma_{h, P}^{2}\right)$ as the market fraction of agent $h(h=I, A)$ adjusted by his risk aversion coefficient and his estimated variance of the ILS, we can get the following equilibrium price of the ILS.

Proposition 3. Under the assumption of $\operatorname{cov}_{A, P S}=0$, the equilibrium price of the ILS is

$$
\mathscr{P}_{o}=r^{-1} \frac{r N_{A, P} \mathscr{G}_{A}+\left(\delta_{I}+r\right) N_{I, P} \mathbb{G}_{I}}{r N_{A, P}+\left(\delta_{I}+r\right) N_{I, P}},
$$

which is stable as $N_{A, P} \delta_{A}<2 R\left(N_{A, P}+N_{I, P}\right)$.

By (20), we can see that if agents are rational enough which means that agents can estimate the (adjusted) coupon of the ILS correctly, that is, $\mathscr{G}_{A}=\mathbb{G}_{I}=g(q)$, then the equilibrium price of the ILS will be equal to the classical price; that is, the discounted coupon $\mathscr{P}_{o}=g(q) / r$. In this case, by (17), there is no trading of the ILS because all agents have the same belief about the ILS coupon. Therefore, we can see that heterogeneous beliefs among agents are the basic condition of trading. In fact, under the condition of heterogeneity in beliefs, we can obtain that the optimal position of the ILS held by agent $A$ is given by

$$
\Theta^{A}=\frac{\left(\delta_{I}+r\right) N_{I, P}}{r N_{A, P}+\left(\delta_{I}+r\right) N_{I, P}} \frac{\mathscr{G}_{A}-\mathbb{G}_{I}}{k_{A} \sigma_{A, P}^{2}}
$$

which means that the greater the belief difference about the ILS, the greater the trading volume of the ILS. In addition, note that the ILS issuance corresponds to $\Theta^{A}>0$; therefore, $\mathscr{G}_{A}>\mathbb{G}_{I}$, which means investors are more optimistic than sponsors, is a necessary condition of the successful issuance of the ILS. In this case, the trading price of the ILS is given by the weighted average of different beliefs about the discounted ILS return; that is,

$$
\mathscr{P}_{o}=\frac{r N_{A, P}}{r N_{A, P}+\left(\delta_{I}+r\right) N_{I, P}} \frac{\mathscr{G}_{A}}{r}+\frac{\left(\delta_{I}+r\right) N_{I, P}}{r N_{A, P}+\left(\delta_{I}+r\right) N_{I, P}} \frac{\mathbb{G}_{I}}{r} .
$$

However, similar to Proposition 2, this equilibrium price is not always stable. The stability of the equilibrium depends not only on the extrapolation rate of agent $A$ as in Proposition 2 but also on the adjusted market fractions of agents. Only when the adjusted market fraction of agent $I$ which corresponds to the supply of the ILS is high enough 
to match the volatility of the ILS demand from agent $A$ which comes from the extrapolative behavior of agent $A$ measured by $\delta_{A}$, then the equilibrium is stable. Otherwise, the price would fluctuate or go to infinity as the cases in Proposition 2.

When the equilibrium price of the ILS exists and is stable, we also care about how other different parameters have the impact on the equilibrium price and the trading volume of the ILS. As follows, we do comparatively static analysis to test it.

Proposition 4 (sensitivity tests). Under the conditions of $\operatorname{cov}_{A, P S}=0$ and $\mathscr{G}_{A}>\mathbb{G}_{I}$,

$$
\begin{gathered}
\frac{\partial \mathscr{P}_{o}}{\partial \operatorname{cov}_{I, P f}}>0, \quad \frac{\partial \Theta_{I}}{\partial \operatorname{cov}_{I, P f}}<0 \\
\frac{\partial \mathscr{P}_{o}}{\partial r}<0, \quad \frac{\partial \Theta_{A}}{\partial r}<0 ; \quad \frac{\partial \mathscr{P}_{o}}{\partial \delta_{I}}<0, \quad \frac{\partial \Theta_{I}}{\partial \delta_{I}}>0 \\
\frac{\partial \mathscr{P}_{o}}{\partial k_{A}}=\frac{N_{A, P}}{\left(\delta_{I}+r\right) N_{I, P}} k_{A} \sigma_{A, P}^{2} \frac{\partial \Theta_{A}}{\partial k_{A}}<0 \\
\frac{\partial \mathscr{P}_{o}}{\partial k_{I}}=-\frac{N_{I, P}}{r N_{A, P}} k_{I} \sigma_{I, P}^{2} \frac{\partial \Theta_{I}}{\partial k_{I}}
\end{gathered}
$$

where $\partial \Theta_{I} / \partial k_{I}>0$ if and only if $\mathscr{G}_{I}>r \mathscr{P}_{o}$.

Equation (23) means when the estimated covariance $\operatorname{cov}_{I, P f}$ between the return of the ILS and the contingent liability of agent $I$ is higher, the ILS supply is lower and furthermore the issue price of the ILS is more expensive. This is because when $\operatorname{cov}_{I, P f}$ increases and especially $\operatorname{cov}_{I, P f}>0$, agent $I$ thinks the ILS needs the greater coupon when there is greater contingent liability. Hence, by (14), in this case, the ILS could increase rather than decrease agent I's risk, which lets him want to decrease his position in the ILS. Thus, the ILS supply decreases and the issue price of the ILS is pushed up.

In addition, the price and the volume of the ILS are also affected by the interest rate and the convergence speed of the ILS to its fundamental value adopted by agent $I$ shown in (24). When the interest rate increases, then the demand of the ILS decreases because agent $A$ likes to put more money in his saving account and furthermore the issue price of the ILS goes down. When agent $I$ uses the quicker convergence speed to adjust his estimation about the redemption price of the ILS, it implies he is more confident to believe that the ILS fundamental value used by himself is a good estimation about the redemption price of the ILS. Furthermore, he likes to supply more ILS which reduces the issue price of the ILS.

For the demand of the ILS coming from agent $A$, it decreases with the increase of his own risk aversion coefficient when there is trading in the ILS or the issuance of the ILS succeeds; that is, $\mathscr{G}_{A}>\mathbb{G}_{I}$. This is because if agent $A$ has greater aversion to risk, then he likes to put more money in his saving account and decrease his ILS demand. Furthermore, it pushes the issue price of the ILS down.

But how the price and the trading volume of the ILS are correlated with the risk aversion coefficient of agent $I$ depends on the relationship between the discounted coupon of the ILS expected by agent $I$ (i.e., $\mathscr{G}_{I} / r$ ) and the issue price $\left(\mathscr{P}_{o}\right)$; see $(26)$. Note that, under the necessary condition $\mathscr{G}_{A}>\mathbb{G}_{I}$ of the successful issuance of the ILS and by (20), the relationship $\mathbb{G}_{I}<r \mathscr{P}_{o}<\mathscr{G}_{A}$ always holds. Then, when $\operatorname{cov}_{I, P f}>0$, we can get $\mathscr{G}_{I}<\mathbb{G}_{I}<r \mathscr{P}_{O}$ and further the supply of the ILS decreases with the increase of the risk aversion coefficient of agent $I$. This case is similar to the covariance case and agent $I$ thinks that the greater values of the liability increasingly correspond to the greater values of the ILS coupon. Therefore, agent $I$ cannot use it to hedge his risk and furthermore the higher the risk aversion coefficient of agent $I$, the lower the supply of the ILS. When $\operatorname{cov}_{I, P f}<0$, if $\mathscr{G}_{I}>\mathscr{G}_{A}\left(>r \mathscr{P}_{o}\right)$, then agent $I$ will not issue the product at $k_{I}<\left(\mathscr{G}_{A}-\mathscr{G}_{I}\right) / \operatorname{cov}_{I, P f}$ (i.e., $\mathbb{G}_{I}>\mathscr{G}_{A}$, which corresponds to the abortion of the ILS issuance) because either agent $I$ thinks that the coupon of the ILS is too high to be issued or agent $A$ is too pessimistic about the product to invest. However, when the risk aversion coefficient of agent $I$ increases beyond $\left(\mathscr{G}_{A}-\mathscr{G}_{I}\right) / \operatorname{cov}_{I, P f}$, considering the protection ability of the ILS because of $\operatorname{cov}_{I, P f}<0$, agent $I$ wants to issue the ILS and increases the supply of the ILS with the increase of his risk aversion coefficient. When $\operatorname{cov}_{I, P f}<0$ but $\mathscr{G}_{I}<\mathscr{G}_{A}$, if $\delta_{I}+r<\left(\left(\mathscr{G}_{I}-\mathscr{G}_{A}\right) / \operatorname{cov}_{I, P f}\right)\left(r n_{A} / k_{A} n_{I}\right)\left(\sigma_{I, P}^{2} / \sigma_{A, P}^{2}\right)$, then $\mathscr{G}_{I}<r \mathscr{P}_{O}$ and agent $I$ wants to issue the decreasing amount of the ILS to hedge his risk with the increase of his risk aversion coefficient. In fact, in this case, the convergence speed adopted by agent $I$ is low, which means that he is not very confident about his estimation of the fundamental price of the ILS. When the risk aversion of agent $I$ increases, he is more and more sensitive to his estimation error such that he adopts the way of reducing the supply of the ILS, which pushes the issue price of the ILS up, to hedge his risk. When $\delta_{I}+r>\left(\left(\mathscr{G}_{I}-\mathscr{G}_{A}\right) / \operatorname{cov}_{I, P f}\right)\left(r n_{A} / k_{A} n_{I}\right)\left(\sigma_{I, P}^{2} / \sigma_{A, P}^{2}\right)$, agent $I$ is very confident about his estimation of the fundamental value of the ILS, which is reinforced by his increasing risk aversion coefficient. Therefore, he supplies more ILS when his risk aversion coefficient increases and, at the same time, the issue price of the ILS is pushed down; see Figure 4.

3.2. Hedging Effectiveness. To be issued successfully, on one side, to investors, the ILS must have the earning ability. In fact, if we substitute (17) into (16), similar to Proposition 1, we can get the relationship of the excess returns between the ILS and the risky asset expected by agent $A$ as follows:

$$
E^{A}\left(R_{P}\right)=\widetilde{\alpha}_{A}+\beta_{A} E^{A}\left(R_{S}\right)
$$

where

$$
\tilde{\alpha}_{A}=-\frac{N_{I, P}}{N_{A, P}} \mathscr{E}^{I}\left(R_{P}\right)\left(1-\rho_{A, P S}^{2}\right)>0, \quad \beta_{A}=\frac{\operatorname{cov}_{A, P S}}{\sigma_{A, S}^{2}} .
$$

From (27), we can see that the "abnormal" return from the ILS is still required by agent $A$ in the flexible supply case, which depends on the supply amount $n_{I} \Theta_{I}\left(=-N_{I, P} \mathscr{E}^{I}\left(R_{P}\right)\right)$ of the ILS, the adjusted market fraction $N_{A, P}$ of agent $A$, and the correlation $\rho_{A, P S}$ between the ILS and the risky asset 


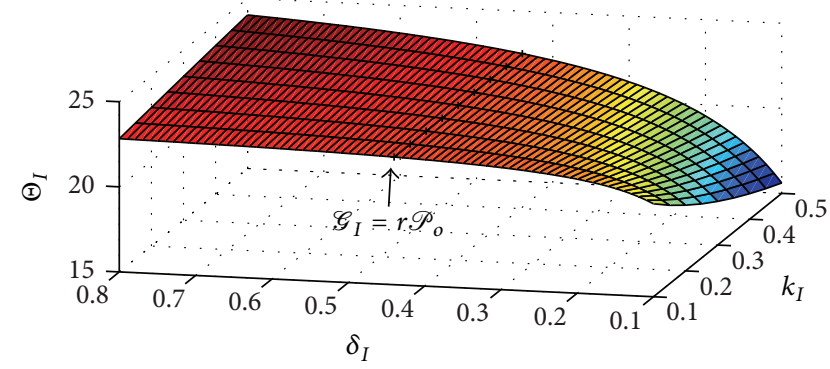

(a) $\Theta_{I}$

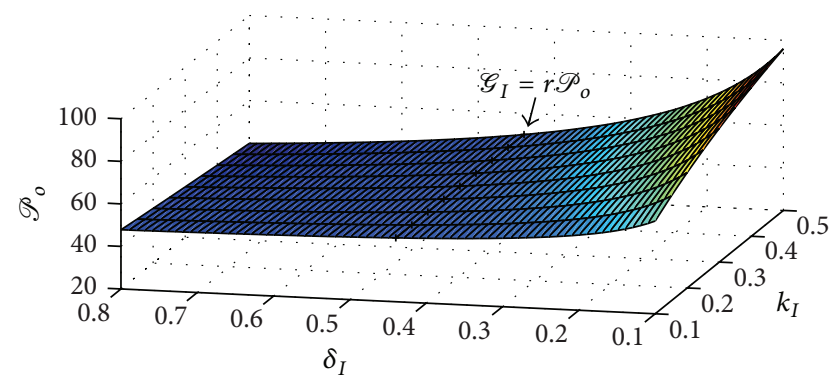

(b) $\mathscr{P}_{o}$

Figure 4: Sensitivity test at $\sigma_{I, P}=\sigma_{A, P}=\sigma_{A, S}=1, \mathscr{G}_{A}=2, \mathscr{G}_{I}=0.5, \operatorname{cov}_{I, P f}=-0.5, E^{A}\left(R_{S}\right)=0.5, r=0.01, n_{I}=1, n_{A}=3$, and $k_{A}=0.2$.

estimated by agent $A$. Thus, similar to the case in Section 2.2, agent $A$ can use the ILS to enhance the efficient frontier of his portfolio.

On the other side, to sponsors, the ILS must be able to be used to hedge their liability risk. If the ILS cannot hedge all the risks that sponsors want to, then there exists the hedging risk (HR) between the recovery provided by the ILS and the contingent liability of sponsors. At least, sponsors could use the ILS to decrease their liability; that is, HR $<f(q)$; otherwise, sponsors would not care to issue this product. In fact, this kind of product has the ability to reduce the liability of sponsors. To illustrate it, we consider a simple case with $\operatorname{cov}_{A, P S}=0$ and $r N_{A, P}=\left(\delta_{I}+r\right) N_{I, P}$ which means agents $A$ and $I$ have the same weight to influence the issue price of the ILS shown in (20). Denote $\widetilde{g}(q)=g(q)+\mathscr{P}_{r}-\mathscr{P}_{o}$ as the real return of the ILS at time 1. If the principal of the ILS was repayable in full at time 1 , then $\widetilde{g}(q)=g(q)$ would be the real coupon; otherwise, the last return of the ILS would be adjusted by the change of the principal amount, that is $\tilde{g}(q)=g(q)+\left(\mathscr{P}_{r}-\mathscr{P}_{o}\right)$. Then we can get the following result.

Proposition 5 (hedging risk). Under the conditions of $\operatorname{cov}_{A, P S}=0$ and $r N_{A, P}=\left(\delta_{I}+r\right) N_{I, P}$, the optimal hedging risk faced by agent $I$ is

$$
\begin{aligned}
H R^{*}= & \frac{r+\delta_{I}}{4 r k_{I} \sigma_{I, P}^{2}}\left(\mathbb{G}_{I}-\tilde{g}(q)\right)^{2} \\
& +f(q)-\frac{r+\delta_{I}}{4 r k_{I} \sigma_{I, P}^{2}}\left(\mathscr{G}_{A}-\tilde{g}(q)\right)^{2} .
\end{aligned}
$$

From (29), we can see that the minimum of the hedging risk can be obtained at $\mathbb{G}_{I}=\widetilde{g}(q)$, which is $f(q)-(r+$ $\left.\delta_{I}\right)\left(\mathscr{G}_{A}-\tilde{g}(q)\right)^{2} /\left(4 r k_{I} \sigma_{I, P}^{2}\right)$. Thus, whether the ILS has the ability to be used to decrease the risk of agent $I$ depends on his own beliefs, but how much the risk of agent $I$ can be hedged relies on the characteristics of his counterpart, agent $A$. In fact, on one side, if agent $I$ has the ability to well understand the underwriting risk and the structure of the ILS such that $\mathbb{G}_{I}=\tilde{g}(q)$, then he can use the ILS to decrease his liability. Otherwise, through the ILS issuance, it could increase the liability burden of agent $I$ instead of decreasing it, as illustrated in Figure 5(a), which is not what agent $I$ wants to see. Therefore, before the ILS issuance, if agent $I$ felt that he had no sufficient understanding about the ILS such that his estimation was not good enough, then maybe agent $I$ would not choose the ILS as his risk management tool, which would directly result in the abortion of the ILS issuance. On the other hand, if the liability can be decreased, then the minimum hedging risk depends on the beliefs of agent $A$. If agent $A$ has bad understanding about the ILS such that there is big difference between his estimated coupon $\mathscr{G}_{A}$ of the ILS and the real return $\tilde{g}(q)$, that is to say that $\left|\mathscr{G}_{A}-\tilde{g}(q)\right|$ is big, then it will favor the decrease of the hedging risk faced by agent $I$. Since great deviation means poor belief, this makes agent $A$ stand in an inferior position. Therefore, agent $I$ can use the poor estimation of agent $A$ to make money and furthermore decrease his hedging risk; see Figure 5(b).

\section{Conclusion and Further Research}

This paper starts with different requirements of investors and/or sponsors based on their own beliefs and constructs a Walrasian equilibrium model to study the pricing factors of an ILS and the condition of the successful issuance of the ILS. Due to the lack of liquidity in the secondary market, we emphasize the static case where investors buy and hold an ILS until maturity. We consider two cases, a fixed issuance volume case and a flexible one.

In the case of the fixed issuance volume, we find that the issuance of an ILS is not always successful. It mainly depends on its issuance volume and return. If the overall volume of new issuance is too high and exceeds the investors' ability to bear risk or the ILS return estimated by investors is too low, both could result in a failure or an abortion of the ILS issuance. When the issuance of an ILS is successful, the ILS must bring the "abnormal" excess return to investors, measured by alpha. Furthermore, the low correlated new asset with high excess return can be used to enhance the efficient frontier of the diversified portfolio of investors.

When we consider that sponsors want to hedge their risk through issuing an ILS, the supply of the ILS is flexible. In this case, the issue price of the ILS is the result of balancing investors' and sponsors' beliefs. In addition, the lower the covariance between the liability of sponsors and the ILS return, the higher the issuance volume needed by sponsors to hedge their risk and further the lower the issue price 


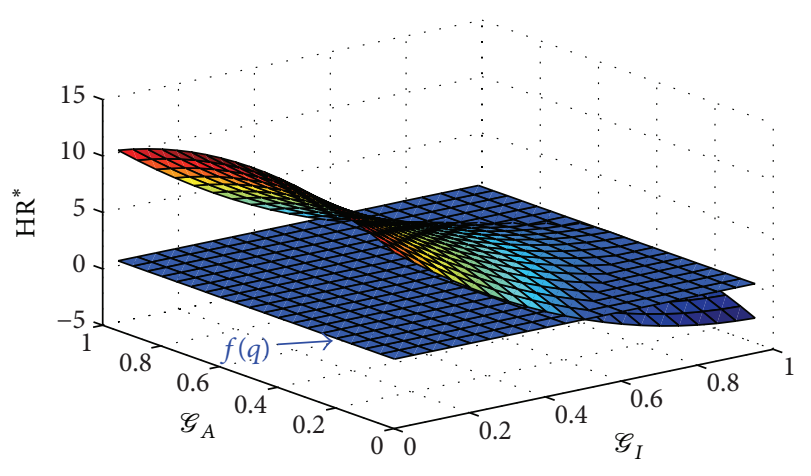

(a) $\operatorname{cov}_{I, P f}=-0.5$

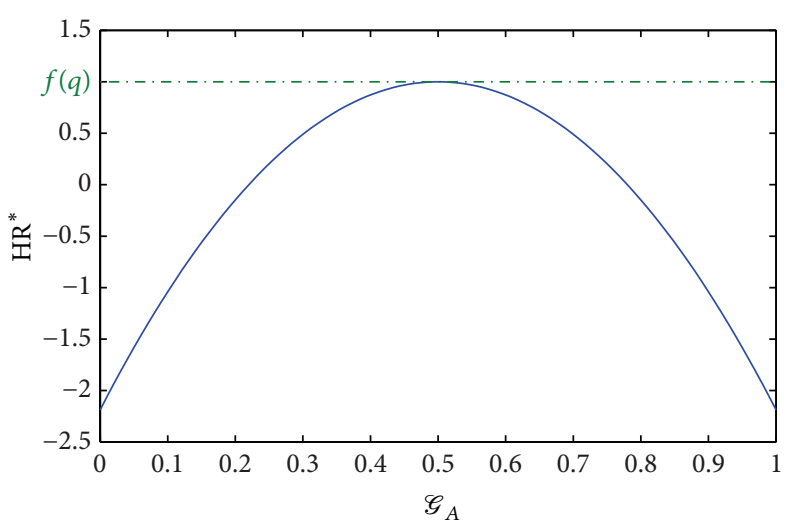

(b) $\operatorname{cov}_{I, P f}=-0.5$ and $\mathbb{G}_{I}=\tilde{g}(q)$

FIGURE 5: Hedging risk at $\tilde{g}(q)=0.5, f(q)=1, \sigma_{I, P}=1, r=0.01, k_{I}=1$, and $\delta_{I}=0.5$.

of the ILS. The higher the interest rate is or the more risk averse investors are, the lower the demand of the ILS from investors is and the lower the issue price of the ILS is. If sponsors are confident about their own estimation of the ILS' fundamental value, the more risk averse they are, the more they supply of the ILS. Otherwise, sponsors decrease the supply of the ILS with the increase of their risk aversion coefficient, which pushes up the issue price of the ILS. The adjustments of the issuance volume and the issue price of the ILS based on the beliefs and needs of investors and sponsors contribute not only to making investors increase their investment performance, but also to improving the hedging ability to sponsors. By further analysis, we show that whether an ILS has the ability to be used to decrease the risk of sponsors depends on the sponsors' understanding about the ILS, but how much the risk of sponsors can be hedged relies on the estimation of investors about the ILS. The better the understanding about the ILS from sponsors or the poorer the estimation for the ILS by investors, the higher the hedging ability of the ILS to sponsors.

In summary, from the fundamental economic concepts, demand and supply, this paper considers different needs from investors and sponsors based on their own beliefs, gives a pricing formula to calculate the issue price of an ILS when its issuance succeeds, and analyzes the impact of different factors on the ILS. So far, we have just considered the static case which is highly suitable for today's market in which investors and sponsors may not find the liquidity to unwind their positions in the ILS. However, we should presumably take a prospective stance. Given the economic benefits from risk diversification and expansion of risk capacity, we expect the ILS market to expand further. Therefore, a multiperiod model or a dynamic model is meaningful. In addition, we consider that investors are myopic mean-variance maximizers in this paper. However, the biggest concern for investors could be the downside risk. As the drawdown following hurricane Katrina in 2005 demonstrates, there is the potential for substantial losses from single events. Therefore, the utility of investors taking the "fat-tail" risk of a significant drawdown into account is more realistic. Moreover, high transaction costs associated with properly securing and executing insurance securitization are also one of the important factors during the ILS trading. Nevertheless, they are beyond the scope of this paper and we leave them for further research.

\section{Appendix}

\section{Proofs of Propositions}

Proof of Proposition 2. Substitute $p_{t}=p_{t-1}=p_{t-2}=p^{*}$ into (11) to get (12). Define $x_{t}=p_{t}-p^{*}$ and then we can rewrite system (11) into the following two-dimensional linear system:

$$
\left(\begin{array}{c}
x_{t} \\
x_{t-1}
\end{array}\right)=\left(\begin{array}{cc}
\frac{2+\delta_{A}}{2 R} & -\frac{\delta_{A}}{2 R} \\
1 & 0
\end{array}\right)\left(\begin{array}{c}
x_{t-1} \\
x_{t-2}
\end{array}\right) .
$$

Based on the criterion of Schur-Cohn, we can see that $p^{*}$ is stable if and only if

$$
\frac{\delta_{A}}{2 R}<1, \quad \frac{2+\delta_{A}}{2 R}<1+\frac{\delta_{A}}{2 R} .
$$

Proof of Proposition 3. We optimize the following problems:

$$
\begin{gathered}
\sup _{\theta_{A, t}, \phi_{A, t}} e_{t}^{A}\left(w_{A, t}\right)-\frac{k_{A}}{2} v_{t}^{A}\left(w_{A, t}\right), \\
\inf _{\theta_{I, t}} e_{t}^{I}\left(h r_{t}\right)+\frac{k_{I}}{2} v_{t}^{I}\left(h r_{t}\right),
\end{gathered}
$$

where $w_{h, t}=\omega_{h} R+\theta_{h, t} R_{P}+\phi_{h, t} R_{S}$ and $h r_{t}=f(q)+\theta_{I, t} R_{P}$. Through the clearing condition $n_{A} \theta_{A, t}=n_{I} \theta_{I, t}$ and the criterion of Schur-Cohn, the result can be obtained.

Proof of Proposition 4. By agents' updating rules of beliefs given by (18) and (19) and the optimal problems (A.3), we can get the optimal positions of the ILS at the equilibrium price:

$$
\begin{gathered}
\Theta_{I}=\frac{\left(\delta_{I}+r\right) N_{A, P}}{r N_{A, P}+\left(\delta_{I}+r\right) N_{I, P}} \frac{\mathscr{G}_{A}-\mathbb{G}_{I}}{k_{I} \sigma_{I, P}^{2}}, \\
\Theta_{A}=\frac{\left(\delta_{I}+r\right) N_{I, P}}{r N_{A, P}+\left(\delta_{I}+r\right) N_{I, P}} \frac{\mathscr{G}_{A}-\mathbb{G}_{I}}{k_{A} \sigma_{A, P}^{2}} .
\end{gathered}
$$


Then,

$$
\begin{gathered}
\frac{\partial \Theta_{I}}{\partial k_{I}}=\frac{\delta_{I}+r}{k_{I}^{2} \sigma_{I, P}^{2}} \frac{N_{A, P}}{r N_{A, P}+\left(\delta_{I}+r\right) N_{I, P}}\left(\mathscr{G}_{I}-r \mathscr{P}_{o}\right), \\
\frac{\partial \Theta_{A}}{\partial k_{A}}=-\frac{\left(\delta_{I}+r\right)^{2} N_{I, P}^{2}}{k_{A}^{2} \sigma_{A, P}^{2}\left(r N_{A, P}+\left(\delta_{I}+r\right) N_{I, P}\right)^{2}}\left(\mathscr{G}_{A}-\mathbb{G}_{I}\right) .
\end{gathered}
$$

The other results are obvious.

Proof of Proposition 5. Note that $\mathrm{HR}=f(q)+\Theta_{I}\left(g(q)+\mathscr{P}_{r}-\right.$ $R \mathscr{P}_{0}$ ) and the optimal position of the ILS held by agent $I$ is given by (A.4). Then, we can get

$$
\mathrm{HR}^{*}=f(q)+\frac{N_{A, P}}{N_{I, P}} \frac{1}{2 k_{I} \sigma_{I, P}^{2}}\left(\mathscr{G}_{A}-\mathbb{G}_{I}\right)\left(\widetilde{g}(q)-r \mathscr{P}_{o}\right) .
$$

Under the assumption $r N_{A, P}=\left(\delta_{I}+r\right) N_{I, P}$ and substituting (20) into (A.7), we can obtain the result.

\section{Conflict of Interests}

The author declares that there is no conflict of interests regarding the publication of this paper.

\section{Acknowledgments}

Financial support from the National Natural Science Foundation of China (11101449, 11301562), the MOE (China) Project of Key Research Institute of Humanities and Social Sciences at Universities (11JJD790004), Beijing Natural Science Foundation (9152016), China Postdoctoral Science Foundation (2014M561038), and the Program for Innovation Research in CUFE is gratefully acknowledged.

\section{References}

[1] P. Nowak and M. Romaniuk, "Pricing and simulations of catastrophe bonds," Insurance: Mathematics \& Economics, vol. 52, no. 1, pp. 18-28, 2013.

[2] F. Bourguignon and C. Morrisson, "Inequality among world citizens: 1820-1992," American Economic Review, vol. 92, no. 4, pp. 727-744, 2002.

[3] A. J. Cairns, D. Blake, and K. Dowd, "Modelling and management of mortality risk: a review," Scandinavian Actuarial Journal, no. 2-3, pp. 79-113, 2008.

[4] J. S.-H. Li and M. R. Hardy, "Measuring basis risk in longevity hedges," North American Actuarial Journal, vol. 15, no. 2, pp. 177-200, 2011.

[5] J. D. Cummins and P. Trainar, "Securitization, insurance, and reinsurance," Journal of Risk and Insurance, vol. 76, no. 3, pp. 463-492, 2009.

[6] P. Barrieu and L. Albertini, The Handbook of Insurance-Linked Securities, John Wiley \& Sons, New York, NY, USA, 2009.

[7] PwC, "Unlocking the potential of ILS," Tech. Rep., PwC, 2012.

[8] S. S. Wang, "A universal framework for pricing financial and insurance risks," Astin Bulletin, vol. 32, no. 2, pp. 213-234, 2002.
[9] Y. Lin and S. H. Cox, "Securitization of mortality risks in life annuities," Journal of Risk and Insurance, vol. 72, no. 2, pp. 227252, 2005.

[10] Y. Lin and S. H. Cox, "Securitization of catastrophe mortality risks," Insurance: Mathematics \& Economics, vol. 42, no. 2, pp. 628-637, 2008

[11] S. H. Cox, Y. Lin, and S. Wang, "Multivariate exponential tilting and pricing implications for mortality securitization," Journal of Risk and Insurance, vol. 73, no. 4, pp. 719-736, 2006.

[12] D. Bauer and J. Ruß, "Pricing longevity bonds using implied survival probabilities," Working Paper, 2006.

[13] M. Denuit, P. Devolder, and A.-C. Goderniaux, "Securitization of longevity risk: pricing survivor bonds with Wang transform in the Lee-Carter framework," Journal of Risk and Insurance, vol. 74, no. 1, pp. 87-113, 2007.

[14] H. Chen and S. H. Cox, "Modeling mortality with jumps: applications to mortality securitization," Journal of Risk and Insurance, vol. 76, no. 3, pp. 727-751, 2009.

[15] D. Bauer, M. Börger, and J. Ruß, "On the pricing of longevitylinked securities," Insurance: Mathematics \& Economics, vol. 46, no. 1, pp. 139-149, 2010.

[16] E. Briys, "Pricing insurance linked bonds," in Options, Futures and Exotic Derivatives, E. Briys and M. Bellalah, Eds., pp. 225240, John Wiley \& Sons, Chichester, UK, 1998.

[17] M. A. Milevsky and S. D. Promislow, "Mortality derivatives and the option to annuitise," Insurance: Mathematics \& Economics, vol. 29, no. 3, pp. 299-318, 2001.

[18] P. Poncet and V. Vaugirard, "The pricing of insurance-linked securities under interest rate uncertainty," The Journal of Risk Finance, vol. 3, no. 3, pp. 48-59, 2002.

[19] M. Dahl, "Stochastic mortality in life insurance: market reserves and mortality-linked insurance contracts," Insurance: Mathematics \& Economics, vol. 35, no. 1, pp. 113-136, 2004.

[20] A. J. Cairns, D. Blake, and K. Dowd, "Pricing death: frameworks for the valuation and securitization of mortality risk," ASTIN Bulletin, vol. 36, no. 1, pp. 79-120, 2006.

[21] A. J. Cairns, D. Blake, and K. Dowd, "A two-factor model for stochastic mortality with parameter uncertainty: theory and calibration," Journal of Risk and Insurance, vol. 73, no. 4, pp. 687718, 2006.

[22] J. Li and A. Szimayer, "The uncertain mortality intensity framework: pricing and hedging unit-linked life insurance contracts," Insurance: Mathematics \& Economics, vol. 49, no. 3, pp. 471-486, 2011.

[23] J. S.-H. Li, "Pricing longevity risk with the parametric bootstrap: a maximum entropy approach," Insurance: Mathematics \& Economics, vol. 47, no. 2, pp. 176-186, 2010.

[24] J. S.-H. Li and A. C.-Y. Ng, "Canonical valuation of mortalitylinked securities," Journal of Risk and Insurance, vol. 78, no. 4, pp. 853-884, 2011.

[25] L. Friedberg and A. Webb, "Life is cheap: using mortality bonds to hedge aggregate mortality risk," The B.E. Journal of Economic Analysis \& Policy, vol. 7, no. 1, article 31, 2007.

[26] R. Mehra and E. C. Prescott, "The equity premium: a puzzle," Journal of Monetary Economics, vol. 15, no. 2, pp. 145-161, 1985.

[27] M. Egami and V. R. Young, "Indifference prices of structured catastrophe (CAT) bonds," Insurance: Mathematics \& Economics, vol. 42, no. 2, pp. 771-778, 2008.

[28] S. H. Cox, Y. Lin, and H. Pedersen, "Mortality risk modeling: applications to insurance securitization," Insurance: Mathematics \& Economics, vol. 46, no. 1, pp. 242-253, 2010. 
[29] M. Milevsky, S. Promislow, and V. Young, "Financial valuation of mortality risk via the instantaneous Sharpe ratio: applications to pricing pure endowments," Working Paper, York University and University of Michigan, 2005.

[30] E. Bayraktar, M. A. Milevsky, S. Promislow, and V. R. Young, "Valuation of mortality risk via the instantaneous Sharpe ratio: applications to life annuities," Journal of Economic Dynamics \& Control, vol. 33, no. 3, pp. 676-691, 2009.

[31] S. H. Cox and H. W. Pedersen, "Catastrophe risk bonds," North American Actuarial Journal, vol. 4, no. 4, pp. 56-82, 2000.

[32] R. Zhou, J. S.-H. Li, and K. S. Tan, "Economic pricing of mortality-linked securities: a tâtonnement approach," Journal of Risk and Insurance, vol. 82, no. 1, pp. 65-96, 2015.

[33] H. Chen, M. Sherris, T. Sun, and W. Zhu, "Living with ambiguity: pricing mortality-linked securities with smooth ambiguity preferences," Journal of Risk and Insurance, vol. 80, no. 3, pp. 705-732, 2013.

[34] A. Beja and M. B. Goldman, "On the dynamic behavior of prices in disequilibrium," The Journal of Finance, vol. 35, no. 2, pp. 235$248,1980$.

[35] W. A. Brock and C. H. Hommes, "A rational route to randomness," Econometrica, vol. 65, no. 5, pp. 1059-1095, 1997.

[36] A. David, "Heterogeneous beliefs, speculation, and the equity premium," Journal of Finance, vol. 63, no. 1, pp. 41-83, 2008.

[37] C. Chiarella, X.-Z.He, and M. Zheng, "Heterogeneous expectations and exchange rate dynamics," European Journal of Finance, vol. 19, no. 5, pp. 392-419, 2013.

[38] G. Gennotte, "Optimal portfolio choice under incomplete information," The Journal of Finance, vol. 41, no. 3, pp. 733-746, 1986.

[39] A. Ziegler, Incomplete Information and Heterogeneous Beliefs in Continuous-Time Finance, Springer Finance Series, Springer, Berlin, Germany, 2003.

[40] G. Favara and Z. Song, "House price dynamics with dispersed information," Journal of Economic Theory, vol. 149, pp. 350-382, 2014.

[41] W. A. Brock and C. H. Hommes, "Heterogeneous beliefs and routes to chaos in a simple asset pricing model," Journal of Economic Dynamics \& Control, vol. 22, no. 8-9, pp. 1235-1274, 1998. 


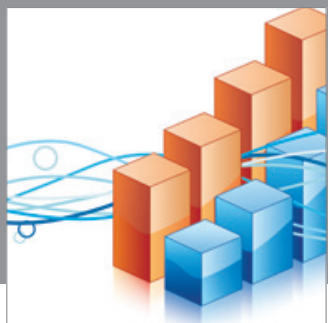

Advances in

Operations Research

mansans

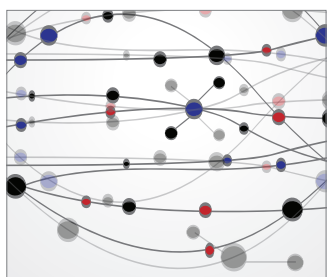

The Scientific World Journal
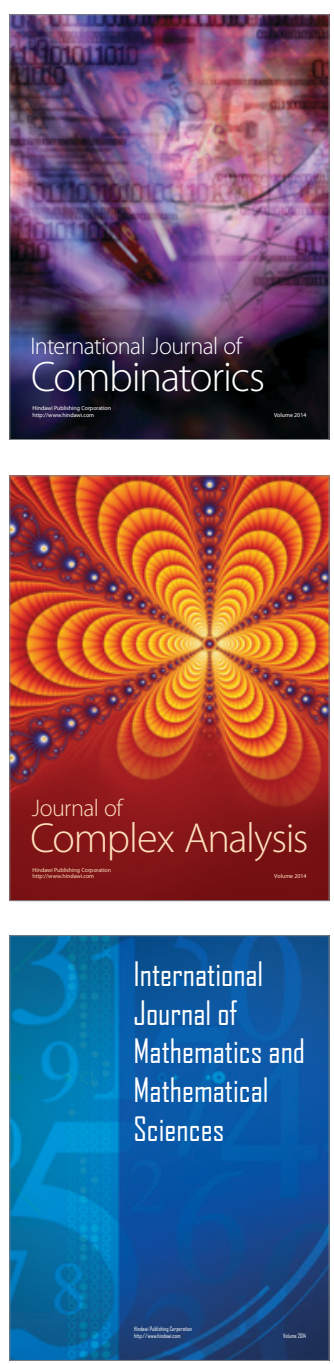
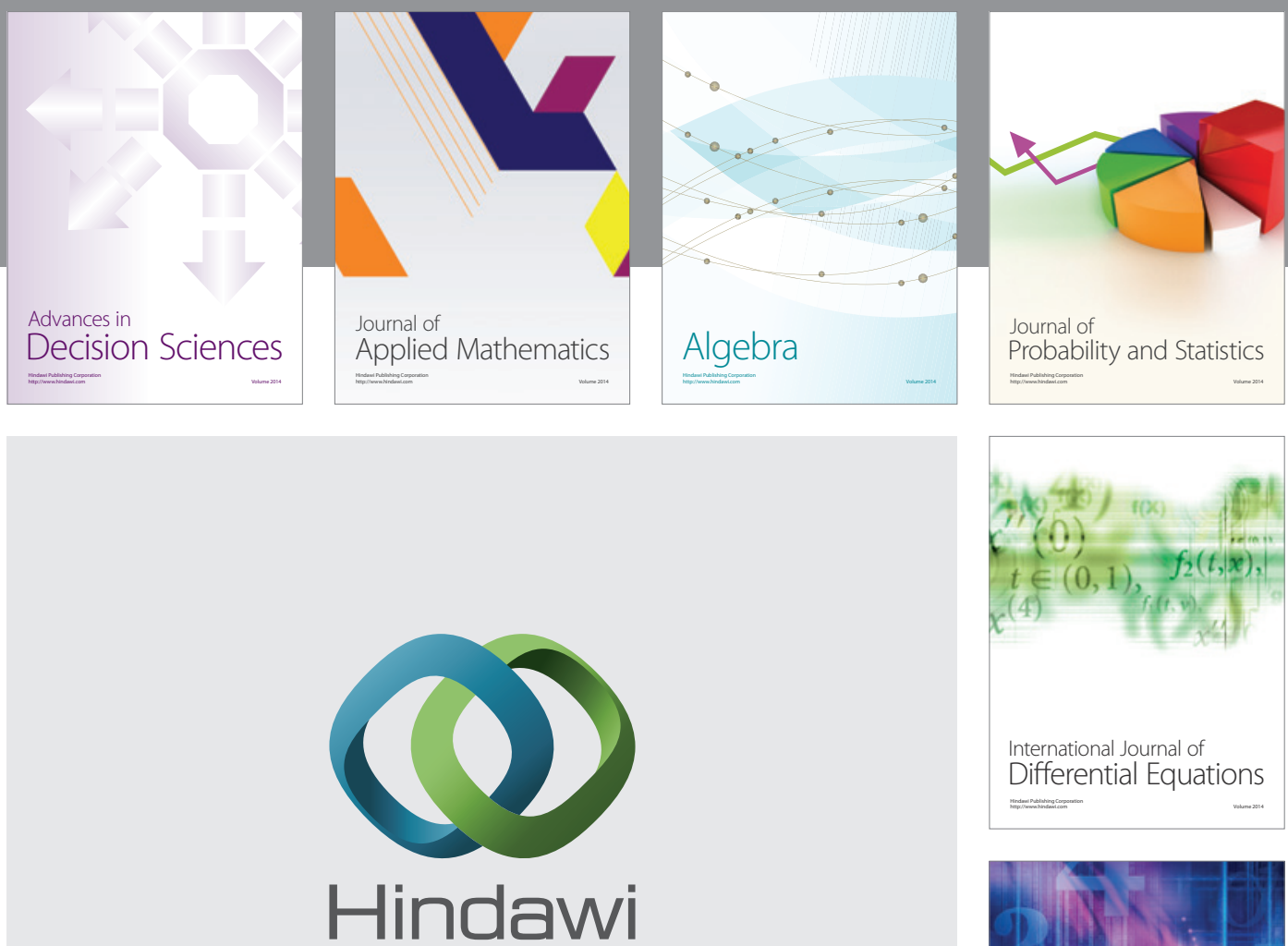

Submit your manuscripts at http://www.hindawi.com
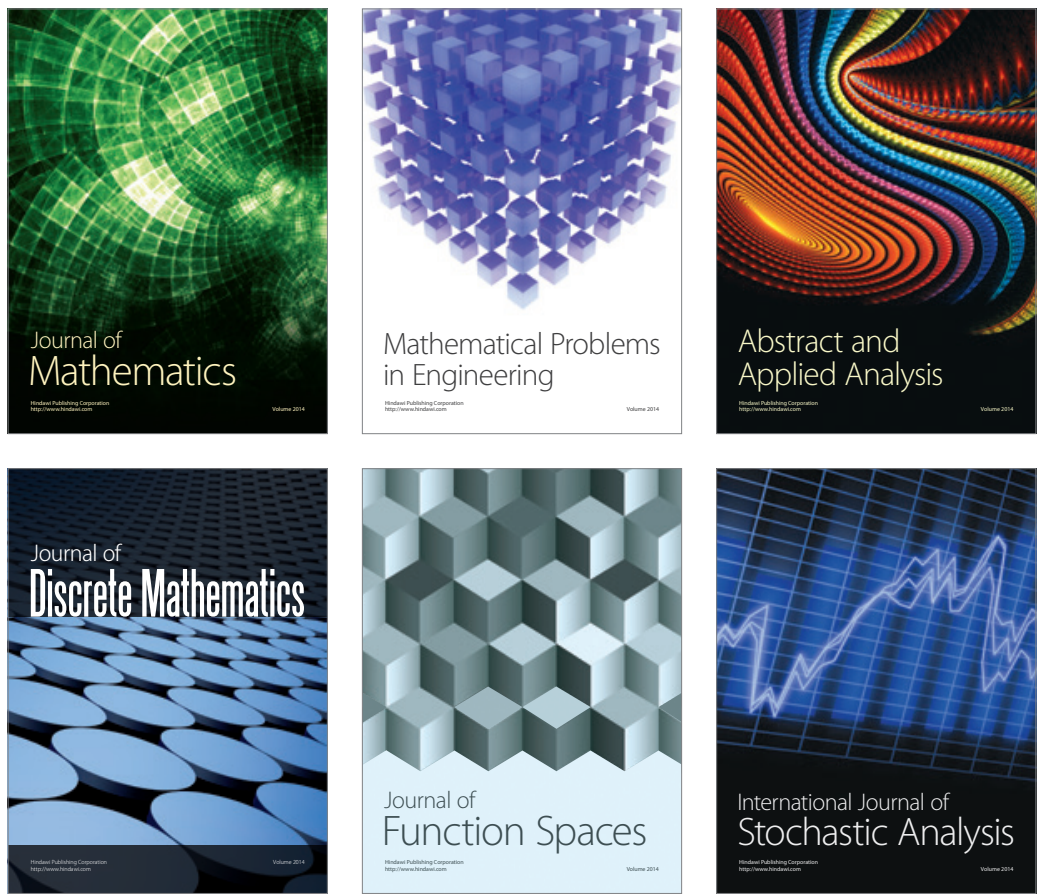

Journal of

Function Spaces

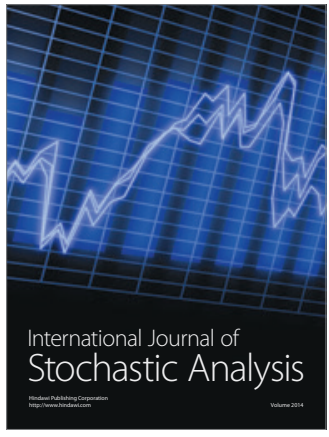

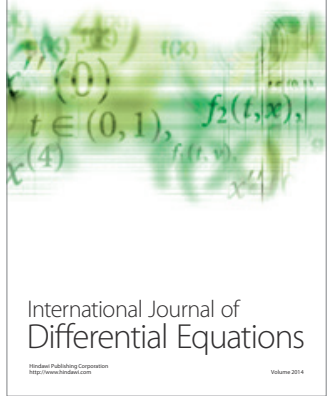
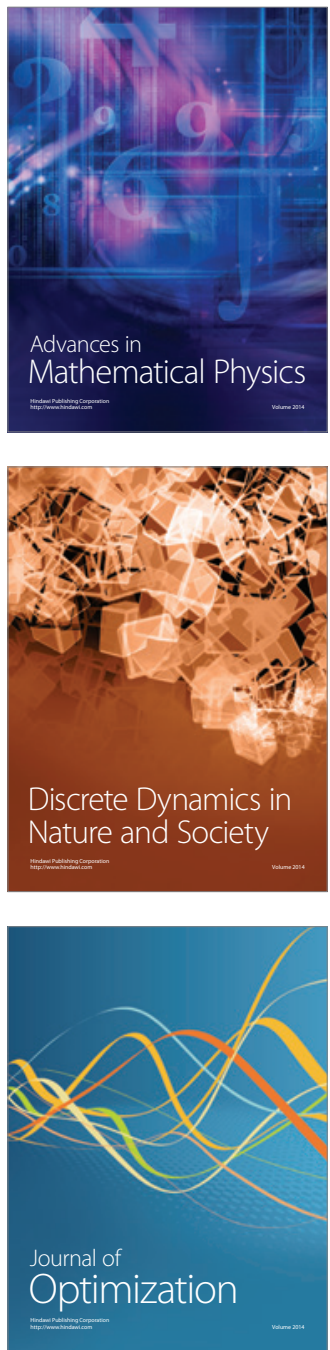